Artikel Penelitian

\title{
Rancang Bangun Mesin Pengupas Buah Pinang
}

\author{
Ade Hendra, Firman Ridwan \\ Jurusan Teknik Mesin, Fakultas Teknik, Universitas Andalas, Padang
}

INFORMASI ARTIKEL

Sejarah Artikel:

Diterima Redaksi: 04 Agustus 2017

Revisi Akhir: 01 September 2017

Diterbitkan: 31 Oktober 2017

\begin{tabular}{l} 
KATA KUNCI \\
\hline Pinang \\
AC motor \\
Concave sleeve \\
KORESPONDENSI \\
\hline
\end{tabular}

E-mail: firmanridwan@ft.unand.ac.id

\section{A B S T R A C T}

In daily life, betel nut is widely used as ingredients of medicines, cosmetic materials and even clothing. Most of rural comunities conventionally process the Betel nut, hence the quality of betel nut has become less. To overcome this, a tool which has a high selling price and save production costs was made. This study aims to develop the skin peel machine. The result shown that the machine was capable to peel 1,066 second/piece using AC motor $1 / 4 \mathrm{hp}$ as an actuator.

\section{PENDAHULUAN}

Tumbuhan yang dikenal sebagai "mahkota dewa" ini diduga pertama kali ditemukan di Papua (Irian). Namun, kemudian lebih berkembang di Jawa, Sumatera dan Kalimantan. Tumbuhan ini dikenal dengan beragam nama lokal, seperti Makutodewo, Drajat, Makotu Ratu, Buah Simalakama, Shian Thao, dan Pau.

Nama saintifik bagi pinang ialah Areca Catechu. Dalam bahasa Hindi buah ini dipanggil supari dan pan-supari sebagai sirih pinang. Tetapi bahasa Malayalam dipanggil adakka atau adekka, Sri Lanka pula dikenali sebagai puvak, Thai sebagai mak dan masyarakat Cina memanggilnya dengan nama pin-lang.

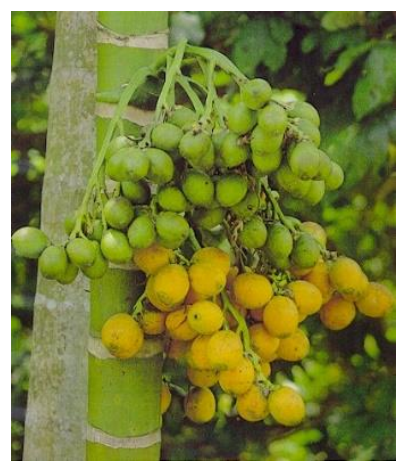

Gambar 1. Buah Pinang

Batang langsing, dapat mencapai ketinggian $25 \mathrm{~m}$ dengan diameter $1 \mathrm{k} 15 \mathrm{Cm}$, tajuk tidak rimbun. Pelepah daun berbentuk tabung dengan panjang 80 $\mathrm{cm}$, tangkai daun pendek; helaian daun panjangnya sampai $80 \mathrm{~cm}$, anak daun $85 \mathrm{kali} 5 \mathrm{~cm}$, dengan ujung sobek dan bergerigi. Tongkol bunga dengan seludang (spatha) yang panjang dan mudah rontok, muncul dibawah daun, panjang lebih kurang $75 \mathrm{~cm}$, 
dengan tangkai pendek bercabang rangkap, sumbu ujung sampai panjang $35 \mathrm{~cm}$, dengan 1 bunga betina pada pangkal, di atasnya dengan banyak bunga jantan tersusun dalam 2 baris yang tertancap dalam alur. Bunga jantan panjang $4 \mathrm{~mm}$, putih kuning; benang sari 6 . Bunga betina panjang lebih kurang $1,5 \mathrm{~cm}$, hijau; bakal buah beruang 1 . Buah buni bulat telur terbalik memanjang, merah oranye, panjang 3,5 - $7 \mathrm{~cm}$, dengan dinding buah yang berserabut. Biji 1 berbentuk telur ada gambaran seperti jala. Tumbuh pada ketinggian $1-1.400 \mathrm{~m}$ dpl. Dibahagian atas (crown) pohon ini berbentuk bulat dan berwarna hijau semasa muda dan apabila masak ia menjadi kuning dan merah. Pinang itu membutuhkan waktu empat tahun untuk berbuah, dan dapat di panen setiap bulannya

Tabel 1. Klasifikasi Ilmiah

\begin{tabular}{l|l} 
Kerajaan: & Plantae \\
\hline Divisio: & Magnoliophyta \\
Kelas: & Liliopsida \\
Ordo: & Arecales \\
Familia: & Arecaceae \\
Genus: & Areca \\
Spesies: & A. catechu
\end{tabular}

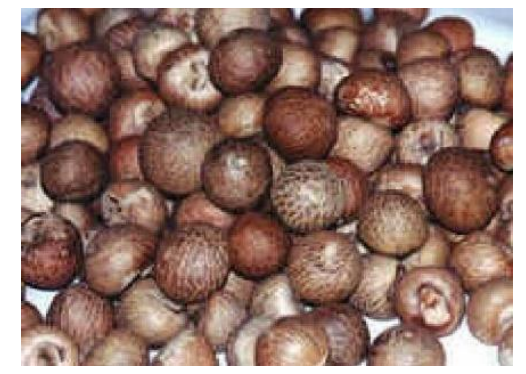

Gambar 2. Biji Pinang

Buah pinang mengandung zat arecaine dan arecoline, sejenis alkaloid yang serupa dengan nikotin, dapat merangsang otak. Zat lain yang dikandung buah ini antara lain arecaidine, arecolidine, guracine (guacine), guvacoline dan beberapa unsur lainnya. Arecolidine adalah penghapus parasit dan cacing serta bertindak seperti asetil kolin. Pinang mengandungi lebih kurang 15\% tanin merah dan $14 \%$ lemak. Tanin dalam pinang digunakan untuk merawat diare. Umbutnya dimakan sebagai lalapan atau dibikin acar. Buahnya boleh digunakan untuk obat. Pucuk Areca Catechu dan pucuk-pucuk dari Areca Borneensis dan Areca Triandra boleh dikonsumsi. Pucuk Areca Hutchinsoniana digunakan sebagai penghilang parasit. Tumbuhan tropika ditanam untuk mendapatkan buahnya dan keindahannya, sebagai hiasan taman tingginya antara 10 hingga $30 \mathrm{~m}$ dan meruncing dibahagian pucuk, ukuran melintang batang $15 \mathrm{~cm}$ hingga $20 \mathrm{~cm}$.

Indonesia merupakan salah satu negara penghasil buah pinang yang cukup penting di dunia, bahkan untuk beberapa komoditas menguasai pangsa pasar dunia. Pentingnya komoditi ini bagi Indonesia, kendatipun menyumbang devisa relatif kecil di bandingkan dengan total nilai ekspor, karena peranannya dalam meningkatkan pendapatan masyarakat cukup besar. Bahkan akhir-akhir ini harga jual buah pinang meningkat yang diiringi dengan meningkatnya penerimaan petani produsen tersebut. Komoditas Saat ini buah pinang sudah menjadi komoditas perdagangan. Umumnya diekspor ke negara-negara Asia selatan seperti India, Pakistan, Bangladesh, Nepal dan sebagainya. Negara-negara peng-ekspor pinang terutama adalah Indonesia, Thailand, Malaysia, Singapura, dan Myanmar. Buah Pinang yang diperdagangkan terutama adalah buah pinang yang telah dikupas sabuknya, dibelah dan dikeringkan. Dinegaranegara importir tersebut buah pinang diolah menjadi semacam permen sebagai makanan kecil. Diperkirakan, populasi pengguna biji pinang secara berkala dalam berbagai bentuk mencapai sekitar 500 juta orang. Sentra produksi buah pinang di Indonesia adalah beberapa propinsi di Sumatera, seperti Sumatera Barat dan Jambi Daerah lain yang sedang mengembangkan komoditi ini di antaranya adalah Kalimantan dan beberapa daerah di Jawa. Kendatipun kontribusi ekspor buah pinang relatif kecil terhadap devisa total Indonesia, namun perkembangan volume dan nilai ekspor komoditi ini meningkat cukup tajam setiap tahunnya.

Prospek ekspor komoditi ini pada masa yang akan datang juga masih cukup besar, seiring dengan semakin tingginya permintaan terhadap obat- 
obatan, bahan pembuatan pakaian, cat, dan bahkan kosmetik dalam industri kosmetika. Prospek ekspor yang cukup besar ini seharusnya mampu diiringi oleh pengembangan budidaya dan industri buah pinang di dalam negeri. Usaha pengembangan ini akan lebih berdaya guna bila usaha kecil yang selama ini dikelola secara tradisional bermitra dengan usaha besar yang pada umumnya lebih menguasai pasar ekspor dan telah memiliki kemampuan teknologi budidaya dan industri buah pinang. Kemitraan yang saling membutuhkan dan saling menguntungkan merupakan landasan utama bagi pengembangan komoditi ini. Dalam rangka menunjang pengembangan budidaya dan industri buah pinang ini diperlukan acuan yang dapat dimanfaatkan baik oleh pengusaha kecil dan pengusaha besar serta perbankan, sehingga memudahkan semua pihak untuk mengimplementasikan proyek ini. Penelitian ini disusun untuk memenuhi tuntutan pihak-pihak yang akan bermitra dalam mengembangkan komoditi buah pinang.

\section{METODOLOGI}

Perancangan dan pembuatan mesin ini dilakukan melalui beberapa proses dimulai dari tinjauan pustaka, yaitu dengan mempelajari teori-teori dasar dari destilasi yang bertujuan untuk mengetahui halhal apa saja yang diperlukan dalam perancangan dan pembuatan mesin serta sebagai acuan dasar sehingga mesin yang dihasilkan memiliki performa yang inginkan. Selanjutnya menentukan kondisi kerja mesin dimana parameter-parameter yang perlu ditentukan anatara lain daya motor, torsi motor dan kecepatan motor serta dimensi dan kondisi buah pinang yang akan dikupas untuk mencari jenis penghempas yang sesuai untuk mendapatkan hasil yang optimal.

Penentuan perancangan dan pembuatan mesin juga harus memperhatikan biaya pembuatan, kecepatan pengupasan, kapasitas produksi, dan kualitas produksi. Langkah selanjutnya adalah perancangan bagian-bagian dari mesin pengupas seperti pencurah material (hopper), concave slave, karet penghempas dan lain-lain. Setelah itu barulah dilakukan proses pembuatan sampai terbentuk mesin pengupas. Pengujian harus dilakukan pada alat agar didapatkan hasil, minimal mendekati hasil yang bagus. Proses akhir yang dilakukan dalam perancangan dan pembuatan ketel penyuling ini adalah jumlah buah yang dihasil persatuan waktu yang dihasilkan pada proses pengupasan. Diagram alir dari proses perancangan dan pembuatan mesin ini dapat dilihat pada Gambar 3.

\subsection{Kondisi Kerja dan Dimensi Alat}

Mesin ini dirancang untuk mengupas kulit buah pinang. Buah pinang yang akan dikupas haruslah sudah dalam kondisi buah masak yang kering dimana sebelumnya telah melewati proses pengeringan dengan cara konvensional yakni dengan sinar matahari.. Lama proses ini tergantung kepada kondisi cuaca, bila dalam kondisi terbaik secara berturut-turut, maka akan membutuhkan lama waktu sekitr 80-100 hari. Hal ini dimungkinkan karena buah yang akan dikupas haruslah dalam kondisi buah yang benar-benar kering, sehingga dapat dikupas dengan baik.

Kondisi buah masak yang kering juga merupakan tingkat kualitas tertinggi yang diinginkan oleh industri-industri ataupun produsen-produsen yang akan mengolah buah pinang ini lebih lanjut, dimana secara tidak langsung dapat menigkatkan daya jual buah ini sendiri.

Alat ini dibuat seperti selinder dengan diameter $600 \mathrm{~mm}$. Dengan ketebalan 300mm. Jika diukur ketinggian total mesin ini adalah $1120 \mathrm{~mm}$ lengkap dengan tinggi hopper $250 \mathrm{~mm}$. Dilihat dari dimensinya mesin ini mudah dipindah-pindahkan. 


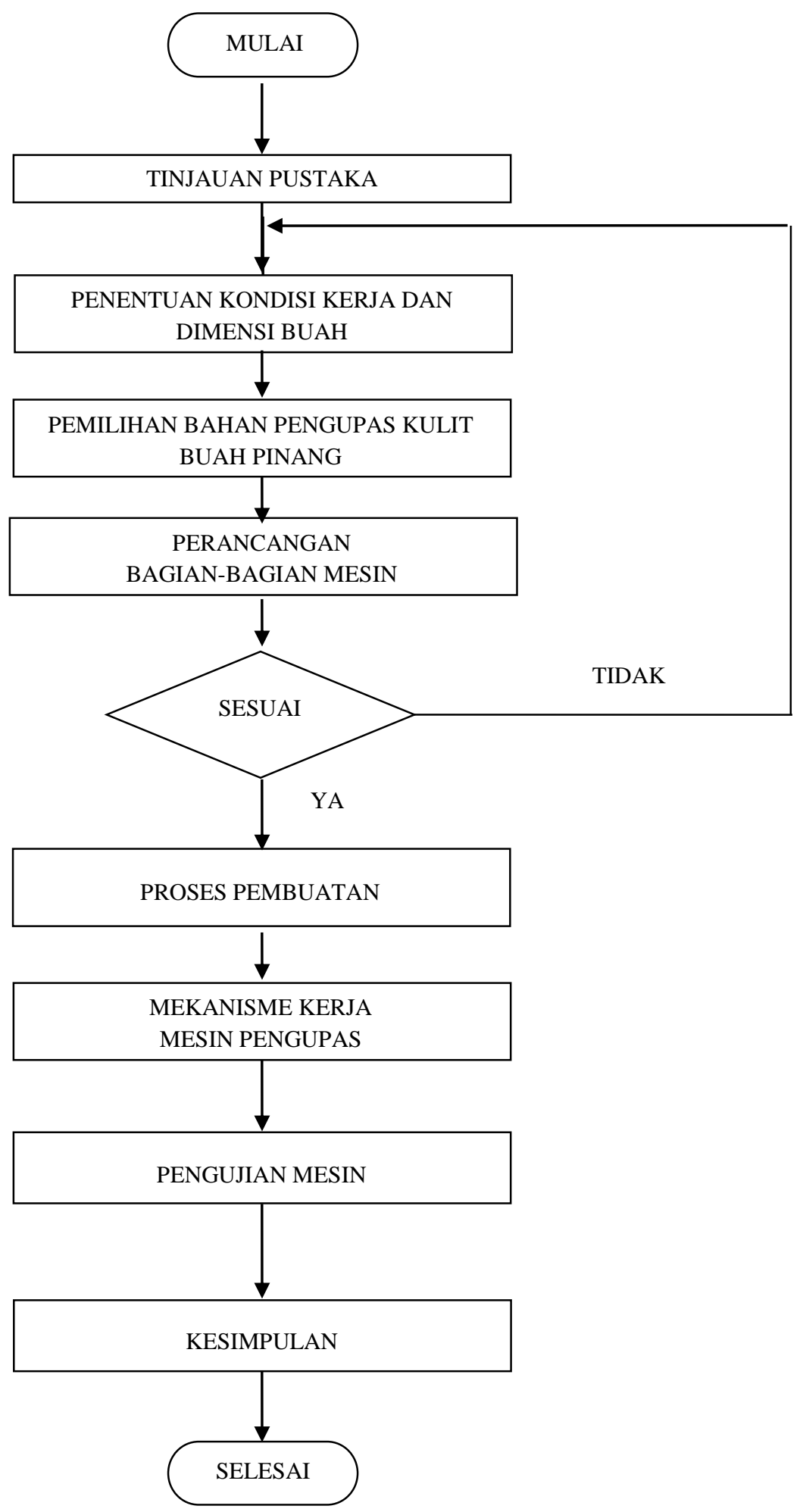

Gambar 3. Diagram Alir Proses Perancangan Mesin

\subsection{Pemilihan Bahan}

Pembuatan mesin ini berdasarkan metode pengupasan untuk menghasilkan hasil yang diinginkan proses pengupasan, bahan dan hasil produksi, kualitas produk, dan mampu beroperasi pada kondisi kerja yang telah ditentukan. Untuk 
mendapatkan pemilihan yang tepat maka haruslah memperhatikan faktor-faktor sebagai berikut :

1. Bahan cangkang mesin.

2. Bahan penghempas buah pinang.

3. Kondisi buah pinang.

4. Proses pengupasan.

5. Kondisi pengisian bahan.

6. Hasil pengupasan.

7. Kecepatan pengupasan.

8. Kapasitas produksi buah yang terkupas.

\subsection{Motor}

Motor AC dengan spesifikasi :

$\begin{array}{ll}\text { Type } & : \text { 42Y5BEPM-E1 } \\ \text { Nominal Voltage } & : 130 \mathrm{AC} \\ \text { No Load Current } & : 1.9 \mathrm{~A} \\ \text { Power } & : 1 / 4 \mathrm{Hp} \\ \text { Nominal Speed } & : 800 \mathrm{rpm} \\ \text { Noinal Torque } & : 16.6 \mathrm{lb} . i n \\ \text { Gear Ratio } & : 5: 1 \\ \text { aka : } & : 1 / 4 \mathrm{hp} \\ \text { Daya } & : 1 / 4 \mathrm{x} 0,746=0,1865 \mathrm{~kW} \\ & : 800 \mathrm{rpm} \\ \text { Putaran motor } & : 800 \times 2 \pi=5024 \mathrm{~m} / \mathrm{min}\end{array}$

\subsection{Perhitungan Motor}

$$
\begin{aligned}
& v=\frac{s}{t} \\
& v=\frac{2 \times \pi \times 0,22 \mathrm{~m}}{0.5 d t}=2,76 \mathrm{~m} / d t \\
& a=\frac{v}{t} \\
& a=\frac{2,76 \mathrm{~m} / d t}{0,5 d t}=5,52 \mathrm{~m} / d t^{2} \\
& F=m \times a \\
& F=10 \times 5,52=55,2 \mathrm{~N} \\
& T=F \times r \\
& T=55,2 \times 0,381=21,03 \mathrm{Nm} \\
& k W=\frac{T . n}{9550000} \\
& k W=\frac{21,03 \times 800}{9550000}=0,176 \mathrm{~kW}
\end{aligned}
$$

\subsection{Prosedur Rancangan}

Alat ini digunakan untuk mengupas buah pinang dengan metode penghempasan. Bagian-bagian utama dari alat ini ialah:

- Pencurah bahan (hopper).

- Pengupasan di dalam cangkang.

- Penampung hasil pengupasan.

Selain merancang, pembuatan dan pengujian terhadap peralatan ini juga harus dilakukan, adapun langkah-langkahnya adalah sebagai berikut :

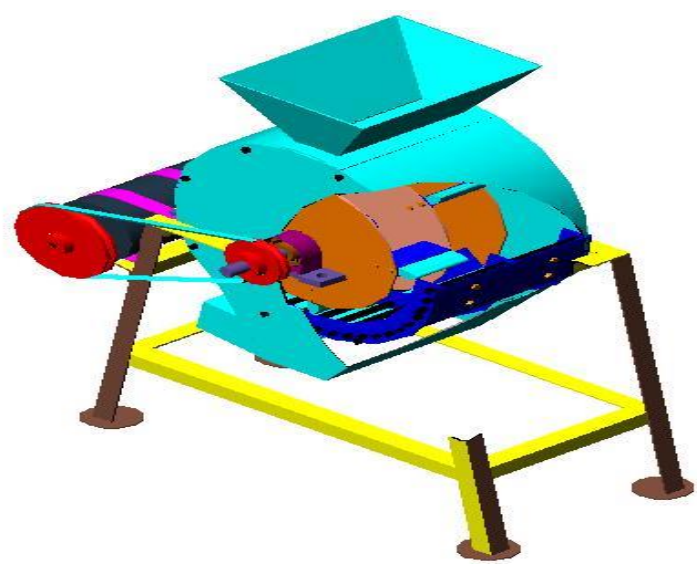

Gambar 4. Rancangan Mesin Pengupas Pinang

\subsection{Concave Slave}

Concave slave diperlukan untuk penahan sekaligus penyaring antara buah dengan biji pinang yang telah dikupas.

1. Pelat strip disiapkan dengan ukuran $\mathrm{mm} \times 400$ $\mathrm{mm}$.

2. Besi nako disiapkan, kemudian di potongpotong dengan panjang $28,5 \mathrm{~mm}$. Sebanyak 29 buah, 4 buah diantaranya digunakan sebagai tulang penyangga.

3. Pelat strip dimalkan dengan karton sehingga didapat 2 buah lingkaran.

4. Masing-masing pelat strip di roling dan disambungkan sehingga didapat dua buah lingkaran yang utuh.

5. Besi nako kemudian disusun dan dilaskan ke plat strip sedemikian rupa dengan jarak yang bervariasi antara 29-31 mm.

6. Pengelasan dilakukan dengan las listrik dan diberikan dudukan sementara agar tidak bergeser. 
7. Besi nako dan pelat strip yang telah dilas akan membentuk Rangka silinder. Rangka ini kemudian dilaskan ke pelat yang telah diroling sebelumnya.

8. Kemudian lubang pemasukan dibuat dibagian atas silinder yang telah di laskan ke rangka, dengan menggunakan grinda dengan ukuran $100 \times 200 \mathrm{~mm}$.
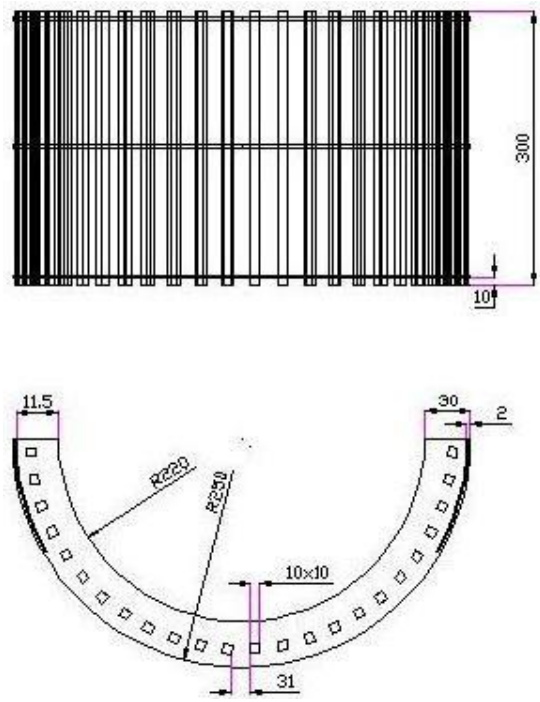

Gambar 5. Ukuran Concave Slave

\subsection{Fungsi Komponen}

Mesin yang dirancang merupakan skala pengujian (laboratorium). Instalasi mesin rancangan ini terdiri dari beberapa bagian yaitu :

1. Silinder tangki.

2. Tutup tangki.

3. Hopper (pencurah material).

4. Concave slave.

5. Dudukan karet pengupas.

6. Karet penggupas/penghempas.

7. Puli.

8. Dudukan motor.

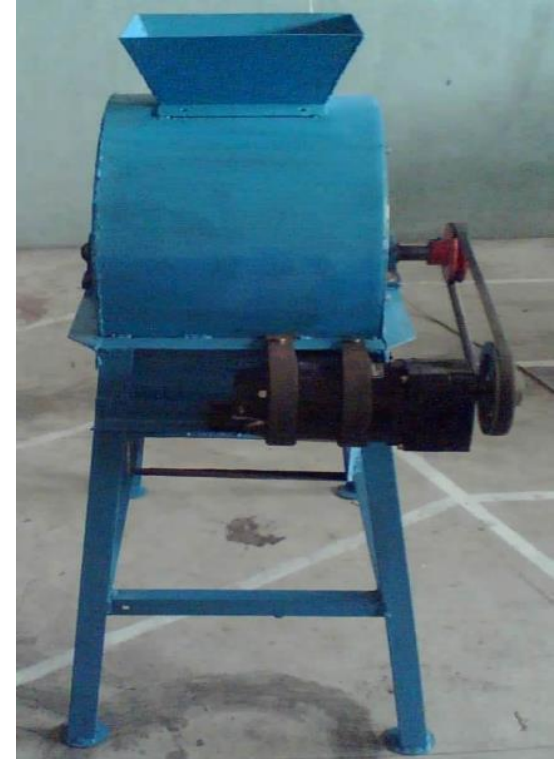

Gambar 6. Mesin Terpasang

\subsection{Pinsip kerja alat}

Buah pinang yang masuk melalui hopper akan langsung ditampung oleh concave slave, disini buah akan dihempas oleh karet pengupas. Karet yang telah dipasang pada dudukan ini akan berputar didalam cangkang, yang akan menghempas buah pinang. Proses ini akan terus berulang-ulang sampai biji buah benar-benar lepas dari kulitnya. Biji yang telah terkupas nantinya akan meluncur masuk menembus concave slave, begitu juga dengan kulitnya. Sedangkan untuk buah yang belum terkupas akan terus dilakukan proses pengupasan.

Proses ini prinsipnya yakni pengupasan menggunakan tangan dan kemudian di coba untuk di aplikasikan dengan menggunakan mekanisasi dengan menggunakan motor.

\section{HASIL DAN PEMBAHASAN}

\subsection{Data Pengujian}

Setelah semua komponen dipasang, temasuk pemasangan motor lalu dilakukan pengujian dengan menghidupkan motor. Didapatkan bahwa motor dapat berjalan dengan baik. Dan didapatkan bahwa Daya yang dibutuhkan mesin sesuai dengan spesifikasi motor untuk dapat menggerakkan dan mengupas biji pinang yakni : 
Asumsi daya motor $k W=\frac{21,03 \times 800}{9550000}=0,176 \mathrm{~kW}$

Spesifikasi Daya motor sebenarnya : $1 / 4 \mathrm{hp}$ : $1 / 4 \times 0,746=0,1865 \mathrm{~kW}$

Dapat dilihat bahwa perhaitungankebutuhan akan daya motor sesuai dengan spesifikasi motor sebenarnya, sehingga dapat dikatakan motor sesuai dengan yang diinginkan.

- Daya yang dibutuhkan min $0,176 \mathrm{~kW}$

- Daya dari motor $0,1865 \mathrm{kw}$

Terlihat bahwa daya yang dibutuhkan lebih kecil dari daya motor, maka mesin dapat berkerja dengan baik. Kemudian dilakukan pengujian motor tanpa beban.

Tabel 2. Perubahan Kecepatan Poros Pengupas terhadap Tegangan

\begin{tabular}{cc}
\hline $\begin{array}{c}\text { Tegangan Motor } \\
\text { Tanpa Beban (Volt) }\end{array}$ & $\begin{array}{c}\text { Kecepatan Poros } \\
\text { Pengupas Tanpa } \\
\text { Beban (rpm) }\end{array}$ \\
\hline 50 & 93,7 \\
75 & 170,1 \\
100 & 243,4 \\
125 & 313,6 \\
150 & 414,1 \\
175 & 479,5 \\
200 & 598,7 \\
\hline
\end{tabular}

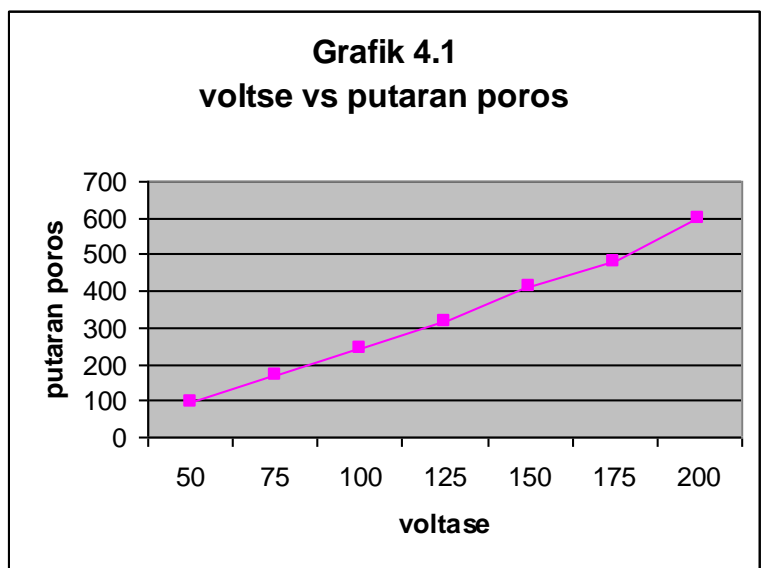

Gambar 7. Grafik Putaran Poros dan Voltase
Kemudian dilakukan pengujian yang sesungguhnya dengan memasukkan buah pinang ke dalam mesin. Hasil yang didapatkan yakni :

Tabel 3. Hasil Pengujian

\begin{tabular}{ccc}
\hline $\begin{array}{c}\text { Tegangan } \\
\text { Motor } \\
\text { (volt) }\end{array}$ & $\begin{array}{c}\text { Jumlah Buah } \\
\text { Yang Masukkan } \\
\text { (Buah) }\end{array}$ & $\begin{array}{c}\text { Waktu Proses } \\
\text { Total } \\
\text { (detik) }\end{array}$ \\
\hline \multirow{2}{*}{150} & 1 & 3,87 \\
& 1 & 2,27 \\
& 1 & 1,98 \\
\hline \multirow{2}{*}{150} & 2 & 3,03 \\
& 2 & 3,04 \\
& 2 & 3,13 \\
\hline \multirow{2}{*}{150} & 3 & 3,72 \\
& 3 & 3,32 \\
& 3 & 4,72 \\
\hline \multirow{2}{*}{200} & 5 & 5,33 \\
& 5 & 3,74 \\
& 5 & 4,45 \\
\hline
\end{tabular}

Waktu rata-rata yang dibutuhkan dalam untuk mengupas buah pinang dengan tegangan 150 volt. Ditunjukkan dengan Grafik 8.

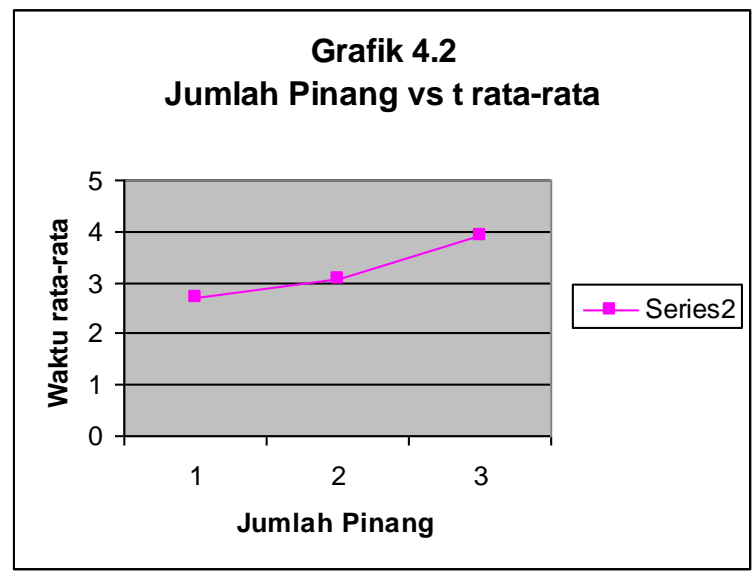

Gambar 8. Grafik Jumlah Pinang Vs Rata-Rata Waktu Kupas

Dengan membandingkan pengupasan secara tradisional (tangan) didapatkan waktu sebesar 
Tabel 4. Waktu Proses Pengupasan

\begin{tabular}{cc}
\hline $\begin{array}{c}\text { Jumlah Buah Yang di } \\
\text { Kupas (Buah) }\end{array}$ & $\begin{array}{c}\text { Waktu Proses Total } \\
\text { (detik) }\end{array}$ \\
\hline 1 & 8,90 \\
2 & 18,62 \\
3 & 25,28 \\
5 & 39,73 \\
\hline
\end{tabular}

Dengan membandingkan hasil yang didapat secara tradisional dengan mekanisasi terdapat perbedaan yang sangat besar, yakni dalam 5 buah pinang $\frac{39,73}{5,33} \times 100 \%=745 \%$

Jika dalam waktu kerja normal yakni 8 jam sehari yang sama dengan 28800 detik, bila dibandingkan maka didapatkan :

- Secara Tradisional : $\frac{39,73}{5}=7,946 \operatorname{det} /$ biji jika dalam 1 hari kerja 8 jam, maka : $\frac{28800 \mathrm{det}}{7,946 \operatorname{det} / \text { biji }}=3624,465$ biji yang terkupas.

- $\quad$ Secara mekanisasi : $\frac{5,33}{5}=1,066 \operatorname{det} /$ biji

Jika dalam 1 hari kerja, maka : $\frac{28800 \mathrm{det}}{1,066 \mathrm{det} / \text { biji }}=27016,885$ biji yang terkupas.

\subsection{Keuntungan Ekonomis}

Jika seorang pekerja digaiji sebesar Rp. 35.000,/hari dengan 'hanya' menghasilkan 3624,465 biji yang terkupas, maka dengan mekanisasi dapat menghemat waktu dan biaya yang sangat besar, yakni

$\frac{27016,885}{3624,465}=7,45$ atau setara dengan 7-8 orang pekerja/ harinya.

7 x Rp.35.000,- = Rp 245.000,-

Jika konsumsi motor dalam 1 hari 186,5 watt x 8 jam x Rp 246 kWh= Rp 367,032,-

\section{KESIMPULAN}

Melihat hasil perbandingan antara proses secara manual dengan proses mekanisasi dan dengan hasil yang cukup memuaskan, dapat dikatakan bahwa tujuan dari penelitian yang ingin dicapai telah berhasil dengan capaian 1,066 det/biji.

Hasil percobaan hasil pengupasan dapat dilihat pada Gambar 9.

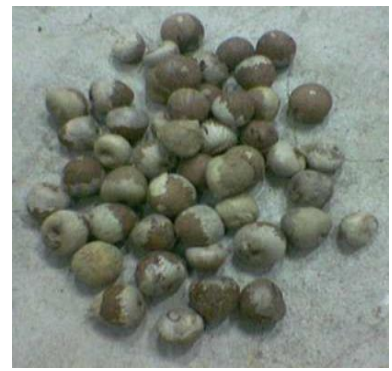

Gambar 9. Hasil Percobaan

Setelah proses berlangsung masih terdapat beberapa kekurangan, agar nantinya dapat diperbaiki di masa yang akan datang, yakni :

1. Bentuk hopper dibuat lebih tinggi dan condong, agar biji ataupun ampas beserta debu tidak keluar melalui hopper.

2. Agar dapat ditambahkan blower, supaya biji dan buah nantinya dapat berpisah pada saat penampungan akhir.

3. Bila digunakan secara massal maka motor dapat diganti dengan motor yang mempunyai daya dan torsi lebih besar, baik itu motor AC ataupun motor AC.

\section{DAFTAR PUSTAKA}

[1] M. F. Spotts. Design of Machine Element, 6th Edition, New Jersey, Prentience-Hall. Inc. 1982

[2] F. P. Beer, E. R. Johnson and J. T. DeWolf, Mechanics of Materials, 3th Editions. SI Units. 2014. New York, Mc Graw-Hill Book Company.

[3] G. Dieter. Engineering Design, 5th Editions. SI Units. New York, Mc Graw-Hill Book Company, 2013.

[4] C. L Dym, L. Pattric, Engineering design, A project based-Introduction. John Wiley \& Sons, 2003.

[5] www.pnm.my/sirihpinang/sp-pinang.htm 